\title{
A seismologically motivated survey of blasting activity in the northern Rhine area
}

\author{
Klaus-G. Hinzen ${ }^{1,2}$ \& Stefan Pietsch ${ }^{1}$ \\ 1 Seismological Station Bensberg, Department of Earthquake Geology, Geological Institute, Universi- \\ ty of Cologne, Vinzenz-Pallotti-Str. 26, D-51429 BERGISCH GLADBACH, Germany \\ 2 corresponding author; e-mail: hinzen@uni-koeln.de
}

Manuscript received: 21 March 1999; accepted in revised form: 6 October 1999

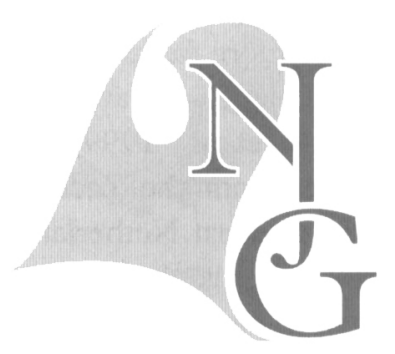

\begin{abstract}
Discrimination between quarry blasts and earthquakes has gained importance due to signature of the Comprehensive Test Ban Treaty. In this context, large chemical explosions are significant. In the routine analysis of data from local seismograph networks, discrimination between smaller blasts and micro-earthquakes is not always clear. Many quarries are in operation and blasts far outnumber natural earthquakes in the highly industrialized northern Rhine area.

We compiled a list of active quarries in the Northern Rhine Area and mapped their locations. We then created a database from a questionnaire sent out to all quarries on the list. From the $33 \%$ of questionnaires that were returned, we discerned some representative values for the main blasting parameters and explosive consumption. In the study area of $72,000 \mathrm{~km}{ }^{2}$, approx. 21,000 blasts are fired per year ( 80 per working day). Most of the blasts ( $72 \%$ ) have total explosive charges between 400 and $4500 \mathrm{~kg}$. Shots with charges above 10 tons are rare (20-30 per year). Some $80 \%$ of the blasts are ripple-fired with a nominal firing time interval of $20 \mathrm{~ms}$.

Based on empirical amplitude vs. distance curves from vibration control measurements, a relation between maximum charge weight per delay time, $\mathrm{L}(\mathrm{kg})$, and a 'quarry blast' magnitude, $\mathrm{M}_{\mathrm{QB}}$, is derived: $\mathrm{M}_{\mathrm{QB}}=0.6 \cdot \log _{10}(\mathrm{~L})+0.131$. Using this relation and extrapolating the database from the questionnaire shows that for magnitudes between 1 and 2, blasts occur 200250 times more frequently than micro-earthquakes in the Northern Rhine area.
\end{abstract}

Keywords: local seismograph network, $\log \mathrm{N}-\mathrm{M}$, magnitude, quarry blasts, seismology

\section{Introduction}

The problem of discriminating nuclear explosions in the subkiloton range from naturally occurring earthquakes and from large chemical explosions focused the interest of the seismological community in recent years on chemical explosions (Baumgardt \& Ziegler, 1988; Smith, 1989; Reamer et al., 1992; Smith, 1993). Additionally, discrimination between small chemical explosions and earthquakes is necessary in local seismograph networks. In some parts of the world, such networks obtain more seismograms from chemical explosions than from natural earthquakes (Richards et al., 1992; Wüster, 1995).

Earthquakes with local magnitudes $M_{L}>2$ in Germany are reported in the annual catalog edited and published by the Federal Institute for Geosciences and Natural Resources in Hannover (see, for instance, Leydecker et al., 1997). While mine tremors, which are man-induced events, are covered by this data catalog, manmade chemical explosions are excluded. Local earthquake catalogs such as the Bensberg catalog of the North Rhine Area do not contain information about blasting activities either.

Richards et al. (1992) described a survey of blasting activity in the United States. They found at least fourteen mines in the western US that fire large chemical explosions with total charge weights of 100500 tonnes ( $\mathrm{t}$ ), many with charges above $40 \mathrm{t}$, and charges exceeding $10 \mathrm{t}$ 'all the time'. Although there is no upper limit for charge weights in Germany, blasts above $10 \mathrm{t}$ total charge weight are rare, the largest ex- 
plosions being around $20 \mathrm{t}$. The main reasons for these limitations are the relatively small size of the quarrying operations and German blast vibration regulations. Due to relatively low natural seismicity, seismological stations in Germany nevertheless record more civil blasts than local earthquakes.

The current technical standard in quarry and mine blasting is ripple-fired explosions. With this blasting technique, the total amount of explosives is distributed over several boreholes; they are detonated with time delays typically in the range of tens of milliseconds. Smith (1989), Hedlin et al. (1989) and Reamer et al. (1992), among others, described the seismic effects of the ripple firing. Hinzen (1988) discussed a seismic method to optimize delay times to reduce blast vibration effects. With some a priori knowledge of the seismic response from blasting, judicious use of ripple firing can both reduce blast vibrations and improve fragmentation of the blasted material.

The continuous record of station BNS in 1997 shows 457 explosions versus 81 local seismic events including mine tremors. In the daily analysis of local seismic networks, blasts are usually easily discriminated on the basis of the seismogram characteristics. Zero depth and ripple firing produce long p-coda; first motions of the p-phase are always upward, and the $\mathrm{S} / \mathrm{P}$ amplitude ratio is usually smaller than for tectonic earthquakes. In some cases, however, discrimination is not easily accomplished, especially if the event was recorded only at a few stations or even one station.

The northern Rhine area is, on a worldwide scale, a low-seismicity area. Approximately twenty damaging earthquakes are known, however, from historical records (Meidow, 1995) and paleoseismic studies (Camelbeeck \& Meghraoui, 1997, 1998). It is important for low-seismicity areas in particular to obtain earthquake catalogs that are not contaminated by blasts in the magnitude range of micro-earthquakes, as these catalogs constitute the basis for seismic risk assessments (De Crook, 1993). Knowledge of the exact location of active quarries and their daily blasting schedules can be helpful in the discrimination of doubtful events or probable explosions. Therefore we tried to collect as much 'ground truth' information about blasting in the area as possible.

We surveyed for the purpose the civil blasting activities within and around the BNS seismograph network. The objectives were (1) to produce a map with all sites of regular blasting activities (locations of active quarries), (2) to estimate statistically the number and size of blasts in the area, and (3) to determine the common blasting techniques. Underground blasting activities play only a minor role in the area of interest.
Blasting in drift production in the coal mines in the Ruhr District, for example, have small charges per delay and are seismologically insignificant. Construction blasts for tunneling or road cuttings were not included in the study; they may have local importance but are only temporary operations that do not effect the network database over time.

\section{Area of interest}

The BNS seismograph network comprises ten stations. The locations of both these short-period stations and the permanent stations operated by other agencies are shown in Figure 1. The dashed rectangle marks the study area. The co-ordinates $49.62^{\circ} \mathrm{N}$, $6.09^{\circ} \mathrm{E}$ and $52.35^{\circ} \mathrm{N}, 9.44^{\circ} \mathrm{E}$ are the lower left and upper right corners of the rectangle, respectively. Most of the area of interest belongs to the state of North-Rhine Westphalia, but parts of Lower Saxony, Hesse, Rhineland Palatinate, Saarland, Belgium, Luxemburg and the Netherlands are also included.

\section{Data collection}

As a first step, we tried to produce a complete list of all active quarries in the area that use explosives in the production process. Since no complete list of explosive consumers in Germany is available from any agency, we used the following three types of databases and sources of information to get an address list of active quarries: (1) governmental authorities, (2) explosives producers, (3) a location map of companies producing natural stone (Stein-Verlag, 1994). Due to a complete list of operations in North-Rhine Westphalia from governmental authorities, all locations of active quarries in this state are known. Some omissions may be present for Hesse and Rhineland Palatinate (due to privacy regulations in Germany, even addresses of quarries and other basic information are sometimes treated as sensitive information by the authorities), but most of the locations are known from the above mentioned sources. Only a few addresses were available for Belgium. The result of the survey was a list with 473 quarries, 286 of which are actively operating with blasting activities in the study area.

As a second step, we sent out questionnaires to all quarries to collect the following information about their blasting activities: (1) the total amount of explosives used per year, (2) the number of blasts per year, month or week, (3) the typical total charge weight of a production blast, (4) the typical maximum charge weight per delay, and (5) the firing-time intervals. In addition, we asked for information about the blasting technique, including the initiation procedure, type of 


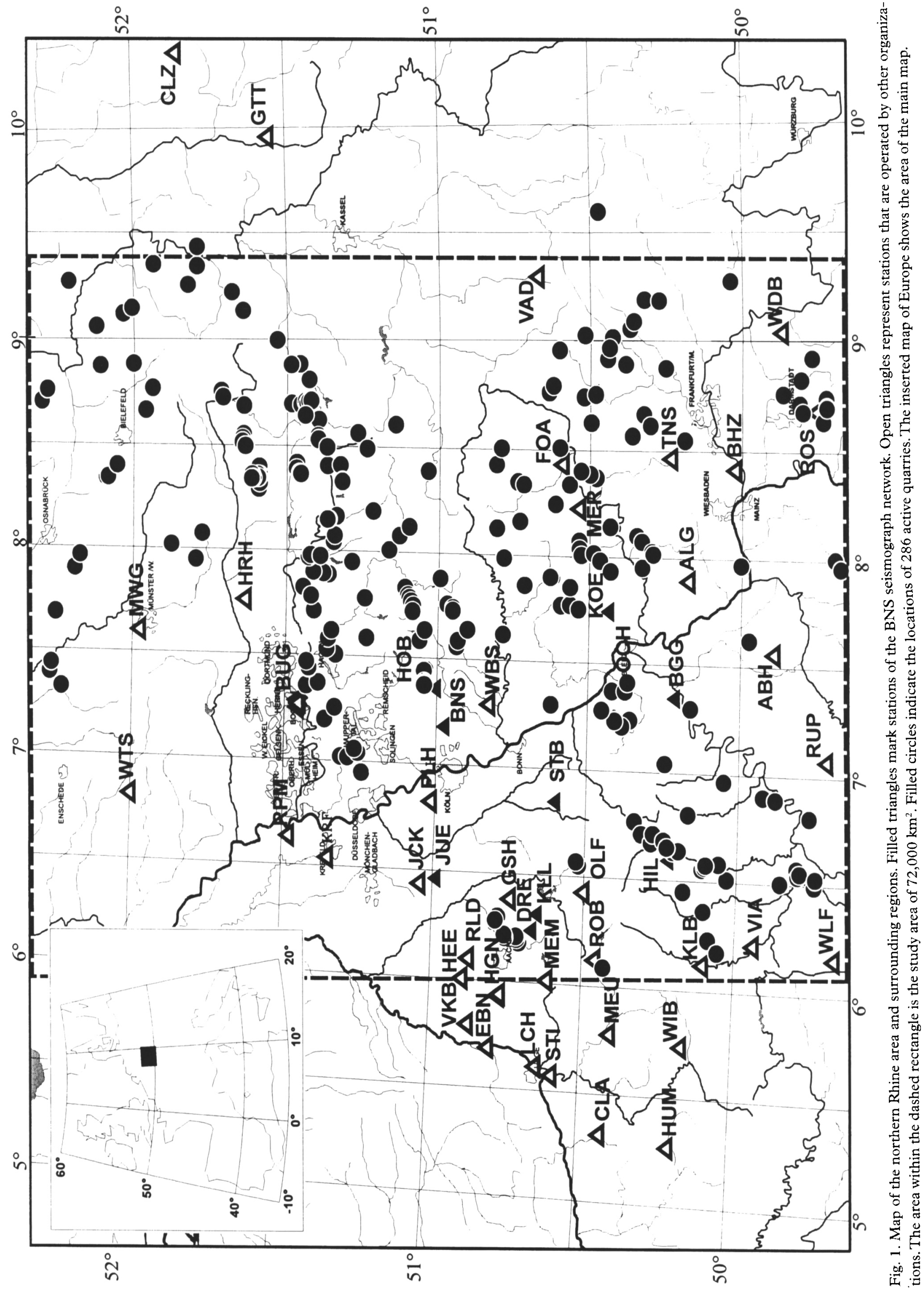


explosives, materials produced and blasting times. From the 286 known active quarries in the study area, 94 questionnaires were returned. Taking into account that it takes some effort to fill out the questionnaires and knowing that some quarries are reluctant to release detailed information about their blasting activities, the return rate of $33 \%$ is quite positive. Answers came from all main deposit areas (Fig. 1). The blasting techniques within one deposit do, as a rule, not differ significantly. The choice of a particular blasting technique depends on the possibilities to optimize productivity and to avoid environmental damage and is therefore strongly influenced by the local geology. The results of the questionnaire therefore should provide a good basis for extrapolation to the total amount of blasts within acceptable bias limits.

\section{Blasting activities in the northern Rhine area}

\section{Location of active quarries}

The 286 sites in the study area (Fig. 1) are concentrated in certain areas where production is controlled by the local geology. In the Eifel, the Westerwald and around the Vogelsberg, typically basalt and other volcanic materials are produced. At the northern border of the study area (Münsterland), most quarries produce limestone. Alternatively, quartz-rich sediments are quarried in the Siegerland. In central Münsterland and within the Lower Rhine Embayment, no quarries exist, due to large covers of soft Tertiary and Quaternary sediments.

\section{Blast sizes}

The typical total charge weight of production blasts and the typical number of blasts performed by the quarries was used for the histogram in Figure 2. The total number of shots covered by the questionnaire is around 7000 per year. Most of these shots (78\%) have a total charge weight in the range of 400-6400 $\mathrm{kg}$. Shots with total charges of, or above, $10 \mathrm{t}$ are rare. The relatively large amount of shots with total charge weights below $50 \mathrm{~kg}$ (401) are mainly blasts from the freestone production. These smaller shots are intended to separate blocks of material without causing damage inside the blocks. These blasts are not relevant for seismological studies because they are usually only detected at very close distances.

Charge weights were used as reported by the quarries and not scaled to equivalent TNT charges. Blasting parameters - like coupling of explosives to borehole walls, firing technique, and groundwater level often have a much stronger influence on the emitted

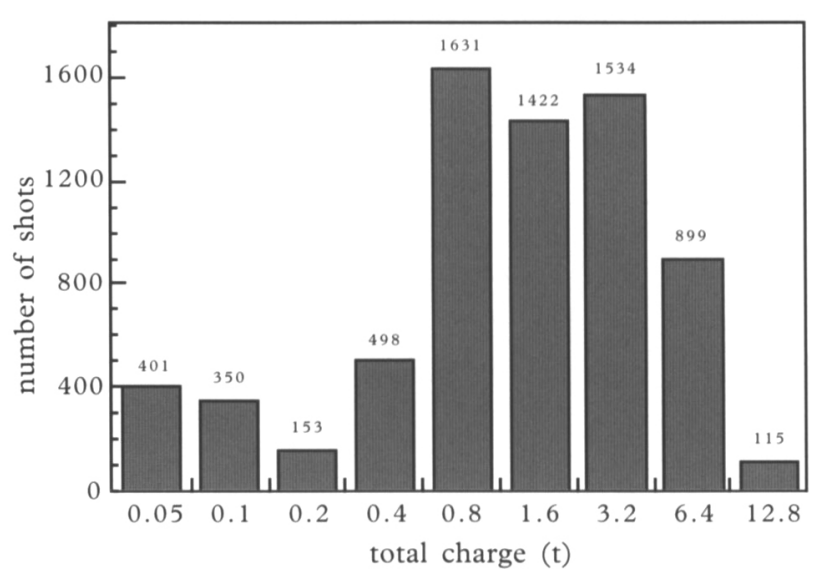

Fig. 2. Histogram of number of shots with respect to total charges in various ranges, as derived from the questionnaires.

seismic energy than the type of explosives used (Lüdeling \& Hinzen, 1986; Chiappetta et al., 1987). Besides the total charge weight, the maximum charge detonated at a single time step during the ripple firing is an important parameter to evaluate ground-vibration levels and the detection range of the blast. The maximum charge per delay could be determined from the questionnaire for approx. 5100 shots per year. The histogram in Figure 3 shows $35 \%$ of these blasts in the range of $25-50 \mathrm{~kg}$ explosives per delay and $84 \%$ in the range of $25-400 \mathrm{~kg}$. The small charges below 10 $\mathrm{kg}$ belong to the freestone production. The largest maximum charge per delay reported by a gravel producer is $850 \mathrm{~kg}$.

Similar to the occurrence of natural earthquakes, larger events due to blasting are much less frequent than smaller events. Richards et al. (1992) presented the data for the continental US in a power law of the form $\mathrm{N}(\mathrm{W})=\mathrm{a} \mathrm{W} \mathrm{W}^{\mathrm{b}}$, where $\mathrm{N}$ is the cumulative counts of blasts equal to, or larger than, the total charge weight, $\mathrm{W}$, whereas a is the total number of blasts. The b-value as in the $\log \mathrm{N}-\mathrm{M}$ curves in earthquake-

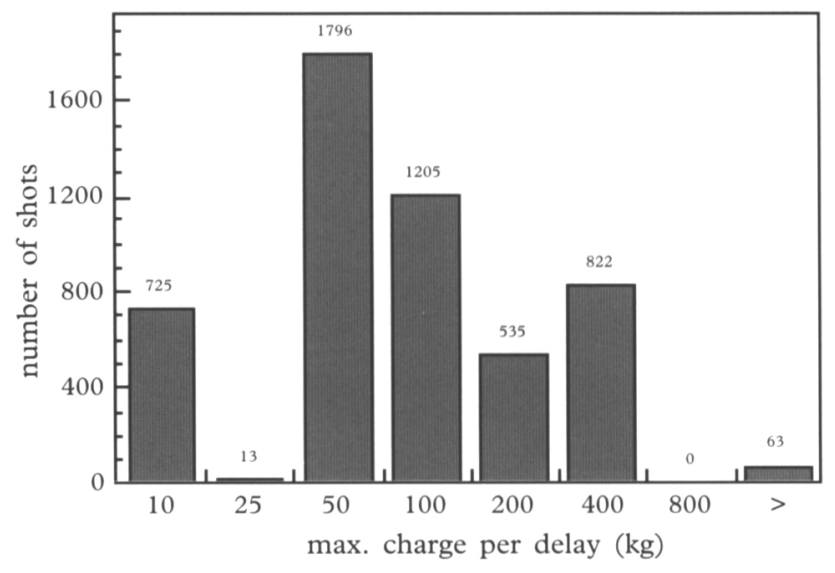

Fig. 3. Histogram of number of shots with respect to maximum charges per delay time interval in various ranges, as derived from the questionnaires. 


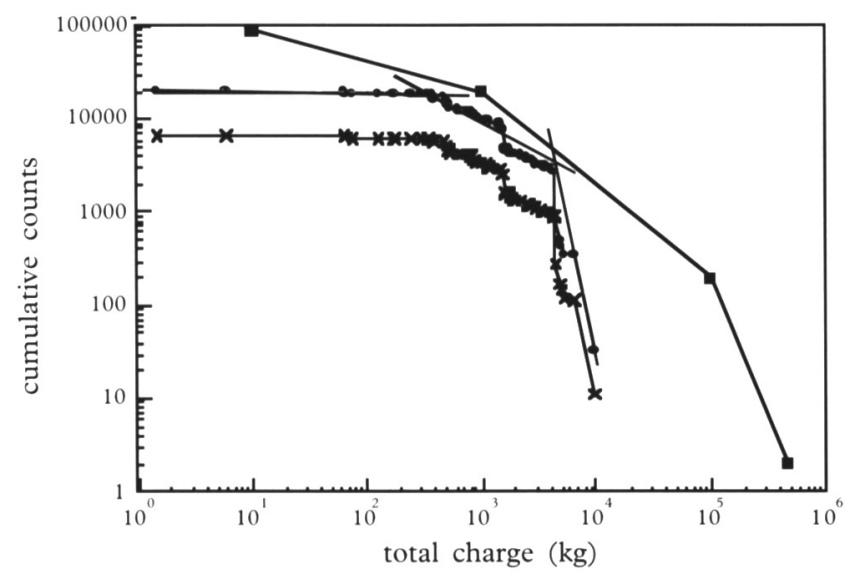

Fig. 4. Cumulative count versus total blast size. Crosses and circles represent the counts of shots from the questionnaires and extrapolated to the total number of shots, respectively. Squares represent data for the US (from Richards et al., 1992).

frequency relations (Gutenberg \& Richter, 1944) describes the relative occurrence of small and large events. Figure 4 shows the cumulative counts versus blast size from the survey data. The blast size is given in metric tons of total charge weight. The crosses represent the data from the questionnaire. Assuming that these values are representative for the study area, and taking into account that the return rate of the questionnaire was $33 \%$, we multiplied these data by a factor of 3 . The filled circles represent the extrapolated total number of shots. Three distinct linear segments are obvious from the $\log / \log$ plot. The first segment of $0.5-380 \mathrm{~kg}$ shows a b-value of $b_{1}=0.01$. The second segment with most of the $380-4500 \mathrm{~kg}$ data has a $b$-value of $b_{2}=0.87$, and in the third segment (above $4500 \mathrm{~kg}$ ) the b-value is $b_{3}=3.85$. Most of the shots with total charge weights under $380 \mathrm{~kg}$ are freestone production blasts.

The most commonly reported blasting technique in the study area uses total charge weights of 380$4500 \mathrm{~kg}$. Larger amounts of explosive are rarely used. Most of the quarry shots are 'Großborhrloch-Reihensprengungen'. This term from the German blasting regulations stands for ripple-fired blasts with bore- holes in one or more rows, where the borehole depth is $12 \mathrm{~m}$ or more. This type of shot accounts for $55 \%$ of the blasts from the survey. A total charge of $400 \mathrm{~kg}$ places a lower bound on efficient ripple-fired row shots. The corner point of the distribution at $4500 \mathrm{~kg}$ is probably due to the German vibration regulations. In Germany, most blasts are initiated by electric detonating systems, which offer up to 20 time steps for the ripple firing (Hinzen, 1990). The maximum charge per delay, which is the main factor determining vibration effects (Dowding, 1985; Lüdeling \& Hinzen, 1986) is, with these initiation systems, in the range of $200 \mathrm{~kg}$. Larger charges per delay often cause vibration problems, particularly in densely populated areas. Electronic detonators offer more time steps, a greater flexibility of firing times and smaller bias in the actual firing times (Hinzen et al., 1987) but are still rarely employed for routine daily production blasts.

Richards et al. (1992) also found a threefold segmented relation for the data in the US (Fig. 4), where the data were taken from blasts monitored by a vibration-control company. For comparison, it has to be taken into account that these data represent only $10 \%$ of the total amount of blasts in the US. Due to differences in the common blasting techniques in quarries and due to the very large shots (above $100 \mathrm{t}$ ) in the coal mine overburden casting, the corner points of the relation are shifted to larger total charge weights compared to the northern Rhine area. Between $1 \mathrm{t}$ and $100 \mathrm{t}$, Richards et al. (1992) found a b-value of unity; almost three-quarters of all blasts have total charge weights between 0.9 and $9 \mathrm{t}$.

\section{Blasting parameters}

Table 1 summarizes the most important blasting parameters from the survey. The minimum, maximum and median and modal values are given for each parameter. The maximum charge per delay is the amount of explosives detonated at the same time step.

Due to the initiation technique, a nominal firing time interval of $20 \mathrm{~ms}$ is used in almost all ripple-

Table 1. Main blasting parameters in the study area as derived from the questionnaires.

\begin{tabular}{|c|c|c|c|c|c|}
\hline & unit & minimum value & maximum value & mode & median \\
\hline explosives consumption & tonnes/year & 0.045 & 1,400 & 30 & 40 \\
\hline total charge per blast & $\mathrm{kg}$ & 0.3 & 16,000 & 1,500 & 1,200 \\
\hline time steps & \# & 1 & 60 & 18 & 15 \\
\hline max. charge per delay & $\mathrm{kg}$ & 0.3 & 937 & 50 & 82.5 \\
\hline borehole length & $\mathrm{m}$ & 1.4 & 32 & 20 & 15 \\
\hline borehole diameter & $\mathrm{mm}$ & 25 & 140 & 90 & 90 \\
\hline burden & $\mathrm{m}$ & 3.0 & 5.0 & 4.0 & 3.9 \\
\hline spacing & $\mathrm{m}$ & 1.0 & 5.5 & 3.0 & 3.5 \\
\hline
\end{tabular}


fired blasts. This basic time interval corresponds to a fundamental frequency of $50 \mathrm{~Hz}$ (Hedlin et al., 1989; Hinzen \& Reamer, 1991; Reamer et al., 1992), which is usually outside the recording range of seismograph stations. It was found that $89.2 \%$ of the blasts are initiated by electric detonators, $4.3 \%$ by electronic detonators, and $5.4 \%$ by non-electric systems (by other methods: $1.1 \%$ ). Detonating cords are used for some $90 \%$ of the blasts, to ensure complete detonation of the entire charge column.

Blasts earlier than 06:00 $\mathrm{h}$ and later than 18:00 $\mathrm{h}$ (local time) are rare. Fixed blasting-time windows are applied by $26 \%$ of the quarries during working days, due to either regulations or the operative procedure (blasts during shift changes). From the blasts recorded at BNS in 1997, some $24.5 \%$ were fired between $11: 00 \mathrm{~h}$ and $12: 00 \mathrm{~h}$, and $59 \%$ between $10: 00 \mathrm{~h}$ and 13:00 h local time.

\section{Frequency of earthquakes and blasts}

In order to compare the frequency of earthquakes and blasts in the study area, it was necessary to estimate the magnitude of quarry blasts. Many studies in vibration analysis for environmental purposes (Koch, 1958; Lüdeling \& Hinzen, 1986; Chiappetta et al., 1987) state that the main factor determining vibration levels at close distances $(2-3 \mathrm{~km})$ is the maximum charge per delay. Regulations request the estimation of vibration levels for new quarry operations. For this purpose, several empirical relations between maximum charge per delay and vibration levels have been derived (Koch, 1958; Behnke, 1970). Böttcher et al. (1977), Böttcher \& Lüdeling (1978) and Lüdeling $\&$ Hinzen (1986) present relations based on peak ground-velocity measurements (PGV) in the distance range from $10 \mathrm{~m}$ to $2 \mathrm{~km}$. For layered sedimentary materials, the vibration distance relation is: $\mathrm{PGV}=$ $969 \cdot L^{0.6} \cdot r^{1.5}$, where $r$ is the distance (in $\mathrm{m}$ ) from the blast and $L$ (in $\mathrm{kg}$ ) is the maximum charge per delay time. For the extrapolation to larger distances, we preferred this empirical relation over one given by the same authors for hard rock, because it seems to represent the amplitude decay for a layered sedimentary medium better.

The PGV is closely related to the amount of seismic energy radiated from a blast (Hinzen, 1998). The local magnitude of earthquakes is based on the measurement of ground displacement with a standard Wood Anderson seismometer (Richter, 1958). Assuming a main signal frequency of $10 \mathrm{~Hz}$ associated with the PGV, we can convert the ground velocity from the above formula to displacement or Wood Anderson amplitudes. With the decay law of $r^{1.5}$ and the calibration used by Richter (with the approximation that a Wood Anderson trace amplitude of $1 \mathrm{~mm}$ at $100 \mathrm{~km}$ distance is assigned a magnitude 3 ), a relation between a quarry blast magnitude, $\mathrm{M}_{\mathrm{QB}}$, and charge weight per delay comes to: $M_{\mathrm{QB}}=0.6 \cdot \log _{10}(L)$ +0.131 . With this formula a magnitude could be estimated for the 5100 blasts for which the maximum charge per delay was specified in the questionnaire. Figure 5 shows the cumulative counts of blasts versus the magnitude as crosses, while the circles are extrapolated data points to estimate the total blasting activity. Like the cumulative counts versus the total charge weight, this graph also yields three linear segments because shots with large total charge weights tend to have larger maximum charges per delay.

Calculation of the magnitudes based on the results from the questionnaires resulted in approx. 60 blasts per year with a magnitude of 2 . With an average detection level of magnitude 1.5 for a distance between 80-100 km, which was the basis for the definition of the study area, the results of the questionnaire shows 1640 blasts per year that could be detected within the BNS network. Assuming a threefold number of blasts for the unanswered questionnaires, we expect roughly 5000 detectable blasts a year, which implies 100 per week or 20 per day, excluding weekends.

Figure 5 also shows the cumulative counts per year for micro-earthquakes (squares) for the Rhine Massif and its northern foreland as derived by Ahorner (1983). This region comprises the study area. The dashed line extrapolates this $\log \mathrm{N}-\mathrm{M}$ curve to magnitudes down to 0.5 . In the magnitude range of 1-2 we expect 200-250 times as many blasts as earthquakes in the study area. At or slightly above magnitude 2, the natural events outnumber the blasts.

\section{Summary and conclusions}

The high demand for natural resources in the heavily industrialized region of the northern Rhine area results in significant quarrying activity. Chemical explosions in the form of quarry blasts outnumber the amount of micro-earthquakes in the area. Most blasts are easily recognized from their seismogram characteristics. In some cases, however, the discrimination is not obvious. For the daily work of local seismograph networks, some 'ground truth' information about quarrying activities can be helpful.

A survey of blasting information was performed for the German part of the northern Rhine area. As a first step, a list of all active quarries was assembled from different sources of information. This list is complete for the state of North-Rhine Westphalia, but maybe deficient for other parts of the study area. With a ques- 


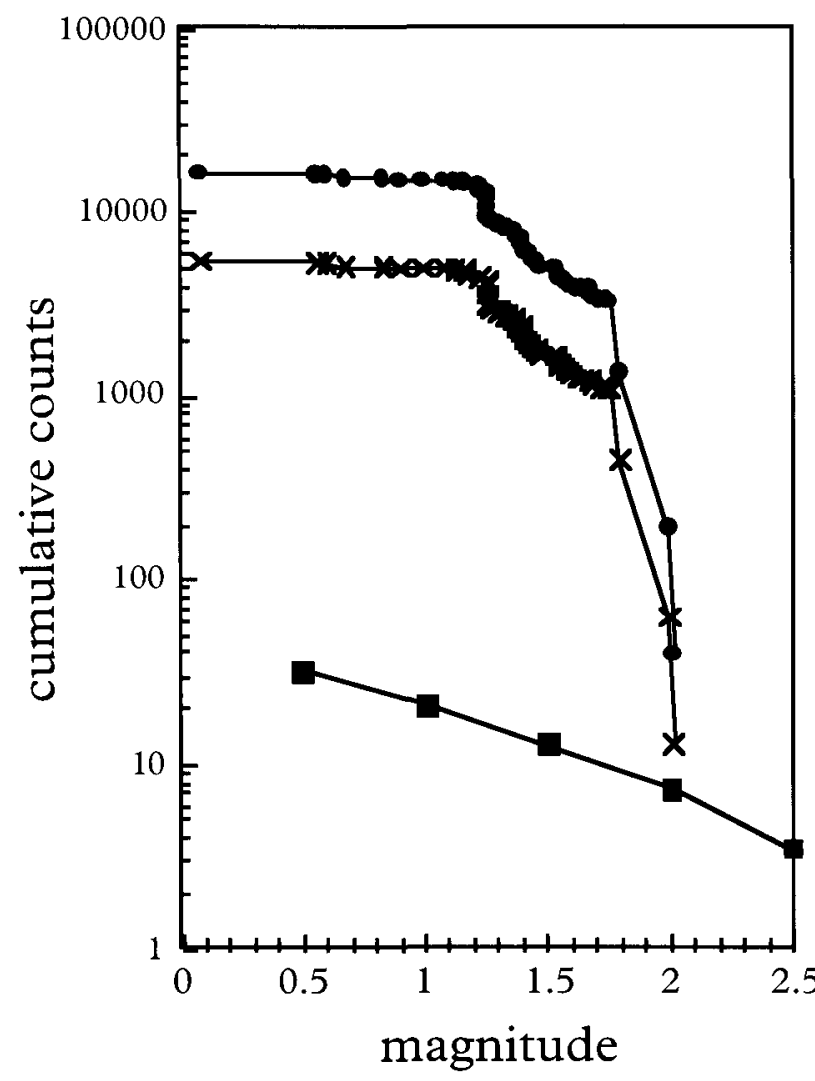

Fig. 5. Cumulative count versus magnitude for quarry blasts and earthquakes in the study area. Crosses and circles represent the counts of shots from the questionnaires and extrapolated to the total number of shots, respectively. Squares represent the number of micro-earthquakes in the study area.

tionnaire sent out to 286 quarries in the study area, $33 \%$ of which were returned, a representative database for common blasting activities was established.

It is estimated that some 21,000 blasts per year are detonated in the study area of $72,000 \mathrm{~km}^{2}$. The modal value of total charge weight per blast is $1.500 \mathrm{~kg}$ of explosives, and $72 \%$ of the blasts have a total charge weight between $0.4 \mathrm{t}$ and $4.5 \mathrm{t}$. Blasts with total charges above $10 \mathrm{t}$ are rare (20-30 per year). By comparing the results to data derived for the continental US, large differences in blasting technique become obvious. Blasts that are seismologically significant on a regional scale with total charge weights above $20-40$ $t$ are missing in the study area. Nevertheless, estimates of magnitude for the quarry blasts based on amplitude/distance relations from vibration control reveal that in the magnitude range from 1-2, blasts are 200-250 times more frequent than micro-earthquakes. This result indicates how important discrimination between blasts and earthquakes becomes for the compilation of earthquake catalogs.

\section{Acknowledgements}

We are thankful to a large number of companies with active quarries, who released their data and took the time to fill out our forms. Without this help the study would not have been possible. We appreciate also the support from several governmental organizations, the Dynamit Nobel AG and the Westspreng $\mathrm{GmbH}$, in our effort to assemble a complete list of active quarries. We thank Sharon Reamer for many helpful hints and the improvement of the English text and K. RoyChowdhury for constructive comments.

\section{References}

Ahorner, L., 1983. Historical seismicity and present-day microearthquake activity of the Rhenish Massif, Central Europe. In: Fuchs, K. et al. (eds.): Plateau uplift. Springer (Berlin): 198221.

Baumgardt, D.R. \& Ziegler, K.A., 1988. Spectral evidence for source multiplicity in explosions: application to regional discrimination of eathquakes and explosions. Bulletin of the Seismological Society of America 78: 1773-1795.

Behnke, C., 1970. Über die Beurteilung der Wirkung von Sprengerschütterungen auf Bauwerke. Geologisches Jahrbuch 98: 514.

Böttcher, G. \& Lüdeling, K., 1978. Forschungsbericht III Bayrischer Alpenraum, Sprengen - Auswirkung gewerblicher Sprengungen im Alpenraum und deren Schadenswirksamkeit, Methoden der Erfassung, Möglichkeiten der Verminderung Bundesanstalt für Geowissenschaften und Rohstoff Hannover (im Auftrag vom Bayrisches Staatsministerium für Arbeit und Sozialordnung, durchgeführt) RB 10/78/15 (München): 91 pp.

Böttcher, G., Lüdeling, R. \& Wüstenhagen, K., 1977. Forschungsbericht II Fränkischer Jura, Sprengen - Untersuchung zur Schematisierung von Erschütterungsintensitäten und deren Wirkungen am Beispiel von Sprengungen. Bundesanstalt für Geowissenschaften und Rohstoffe Hannover (im Auftrag vom Bayrisches Staatsministerium für Arbeit und Sozialordnung) RB 10/77/09 (München): 125 pp.

Camelbeeck, T. \& Meghraoui, M., 1997. Large earthquakes in northern Europe more likely than once thought. EOS 77: 405+ 409.

Camelbeeck, T. \& Meghraoui, M., 1998. Geological and geophysical evidence for large paleo-earthquakes with surface faulting in the Roer Graben (northwest Europe). Geophysical Journal International 132: 347-362.

Chiappetta, R.F., Morhard, R.C., Borg, D.G. \& Sterner, V.A., 1987. Explosives and rock blasting. Atlas Powder Company, Field technical operations (Dallas): $662 \mathrm{pp}$.

De Crook, Th., 1993. Probabilistic seismic hazard assessment for the Netherlands. Geologie en Mijnbouw 72:1-13.

Dowding, C.H., 1985. Blast vibration monitoring and control. Prentice Hall (Englewood Cliffs): $297 \mathrm{pp}$.

Gutenberg, B. \& Richter, C.F., 1944. Frequency of earthquakes in California. Bulletin of the Seismological Socety of America 38: 185-188.

Hedlin, M.A.H., Minster, J.B. \& Orcutt, J.A., 1989. The time frequency characteristics of quarry blasts and calibrations in Kazakhstan, USSR. Geophysical Journal International 99:109-121.

Hinzen, K.-G., 1988. Modelling of blast vibrations. International Journal on Rock Mechanics, Mineral Science \& Geomechanics Abstracts 25 (6): 439-445.

Hinzen, K.-G., 1990. Moderne Techniken zur Erfassung, Bearbeitung und Beeinflussung von Sprengerschütterungen unter 
besonderer Berücksichtigung elektronischer Zünder. Nobel Hefte 56:103-112.

Hinzen, K.-G., 1998. Comparison of seismic and explosive energy in five smooth blasting test rounds. International Journal of Rock Mechanics and Mineral Science 35: 957-967.

Hinzen, K.-G. \& Reamer, S.K., 1991. Effect of firing time variations and explosives array length on seismic wave propagation from quarry blasts. Proceedings $17^{\text {th }}$ Conference on Explosives and Blasting Techniques (Las Vegas): 114-123.

Hinzen, K.-G., Lüdeling, R., Heinemeyer, F., Röh, P. \& Steiner, U., 1987. A new approach to predict and reduce blast vibrations by modelling of seismograms and using a new electronic initiation system. Proceedings $13^{\text {th }}$ Conference on Explosives and Blasting Techniques (Miami): 144-161.

Koch, H.W., 1958. Zur Möglichkeit der Abgrenzung von Lademengen bei Steinbruchsprengungen nach festgestellten Erschütterungsstärken. Nobel Hefte 24: 92-96.

Leydecker, G., Henger, M. \& Schick, A., 1997. Data catalogue of earthquakes in Germany and adjacent areas 1993. Bundesanstalt für Geowissenschaften und Rohstoffe: $165 \mathrm{pp}$.

Lüdeling, R. \& Hinzen, K.-G., 1986. Erschütterungsprognose und Erschütterungskataster - Forschungsarbeiten auf dem Gebiet der Sprengerschütterungen. Nobel Hefte 213: 105-123.

Meidow, H., 1995. Rekonstruktion und Reinterpretation von historischen Erdbeben in den nördlichen Rheinlanden unter Be- rücksichtigung der Erfahrungen bei dem Erdbeben von Roermond am 13. April 1992. Dissertation, Geologisches Institut Universität Köln: 305 pp.

Reamer, S.K., Hinzen, K.-G. \& Stump, B.W., 1992. Near-source characterization of the seismic wavefield radiated from quarry blasts. Geophysical Journal International 110: 435-450.

Richards, P., Anderson, D.A. \& Simpson, D.W., 1992. A survey of blasting activity in the United States. Bulletin of the Seismological Society of America 82: 1416-1433.

Richter, C.F., 1958. Elementary seismology. Freeman and Company (San Francisco): 768 pp.

Smith, A.T., 1989. High-frequency seismic observations and models of chemical explosions: implications for the discrimination of ripple-fired mining blasts. Bulletin of the Seismological Society of America 79: 1089-1110.

Smith, A.T., 1993. Discrimination of explosions from simultaneous mining blasts. Bulletin of the Seismological Society of America 83: $160-179$.

Stein-Verlag, 1994. Standortkarte Naturstein Rheinland-Ruhrgebiet, Mittelrhein-Pfalz-Saar. Stein-Verlag Baden-Baden $\mathrm{GmbH}$ (Iffezheim).

Wüster, J., 1995. Diskrimination von Erdbeben und Sprengungen im Vogtlandgebiet und Nordwest-Böhmen. Dissertation; Berichte des Instituts für Geophysik der Ruhr-Universität Bochum A 42: $211 \mathrm{pp}$. 